\title{
Occurrence of infection with a parvovirus-like agent in children with sickle cell anaemia during a two-year
} period

\author{
MJ ANDERSON, LR DAVIS, ${ }^{*}$ J HODGSON $₫$ SE JONES, L MURTAZA, $†$ JR PATTISON, \\ CE STROUD, $\dagger$ JM WHITE*
}

From the Departments of Medical Microbiology, ${ }^{*}$ Haematology and $†$ Child Health, King's College Hospital Medical School, Denmark Hill, London SE5 8RX

SUMMARY The occurrence of infection with a parvovirus-like agent during the period April 1979-May 1981 in children attending a single sickle cell clinic in London was investigated. Virus was detected in serum by counter-current immunoelectrophoresis (CIE) and immunoelectron microscopy (IEM). Viral antibody was detected by CIE and specific IgM antibody by an IgMantibody capture assay. Of the 68 children studied nine presented in aplastic crisis and evidence of infection with the parvovirus-like agent at the time of the crisis was found in all nine. Eighteen of the other children were antibody-positive at some time during the study. In 11 children there was no evidence of recent infection; however, two of these had a history of aplastic crisis in previous years. The other seven seroconverted during the course of the study but did not show any haematological effects. Five of these had a primary infection, one appeared to have reinfection and in the seventh there were insufficient data to distinguish between the two. Possible explanations for the difference between those presenting with aplastic crisis and those with asymptomatic seroconversion are discussed.

In 1975 Cossart et al described the presence of parvovirus-like particles in the sera of 11 persons. $^{1}$ Nine were healthy blood donors, one was a case of acute hepatitis and one had been given a renal transplant a week earlier. The serum from one of the healthy blood donors was designated B19. Subsequently a similar virus was found in the serum of two blood donors ${ }^{2}$ (one of whom felt unwell and vomited several times and the other complained of myalgia at about the time of the viraemia) and in two patients with a short febrile illness. ${ }^{3}$

We recently reported ${ }^{45}$ an association between a virus which cross-reacts with that found in serum B19 and aplastic crises in children with sickle cell anaemia (SCA). In order to minimise morbidity and mortality children with SCA are admitted to hospital promptly for observation and investigation even when they are suffering apparently minor illness. Investigation of these patients after admission to hospital includes the taking of serum samples for

$¥$ Seconded from the Public Health Laboratory, Dulwich Hospital, London SE22 8QF.

Accepted for publication 9 December 1981 virus studies and the storage of these samples permits retrospective surveys. This report is concerned with the occurrence of infection with a parvoviruslike agent and associated symptoms in children with sickle cell anaemia during a two-year period.

\section{Material and methods}

PATIENTS

From 1960-1980, 224 children with SCA attended King's College Hospital. They were almost equally divided between those of West Indian and those of West African origin. They are seen regularly at the sickle cell clinic and their parents are encouraged to bring them to hospital if they are at all unwell. The number of children attending each year grew steadily until 1972, since when it has varied from 69 to 83. Changes are due to movement of individuals away from South London or transfer to the adult clinic during their teens.

HAEMATOLOGICAL INVESTIGATIONS

The diagnosis of SCA was based on characteristic peripheral blood findings and the results of haemo- 
globin electrophoresis. All appeared homozygous for $\mathrm{HbS}$ but the possibility of $\mathrm{HbS} / \beta^{\circ}$ thalassaemia could not be excluded in every case. HbF concentrations were determined by a standard alkaline denaturation technique.

\section{VIRUS STUDIES}

Sera taken for routine investigation during the period April 1979-May 1981 at either an outpatient visit or on hospital admission were used for virus studies. Specimens were stored at $-20^{\circ} \mathrm{C}$ prior to testing.

The presence of virus antigen in sera was detected initially by counter-current immunoelectrophoresis (CIE) as previously described..$^{5}$ Immunoelectron microscopy was performed by a standard method. ${ }^{6}$ Virus antibody was detected by CIE and specific IgM antibody by an IgM antibody capture radioimmunoassay using previously described methods. ${ }^{57}$ Immunodiffusion tests were performed using cellulose-acetate strips. ${ }^{8}$

\section{Results}

\section{CASES OF APLASTIC CRISIS}

Occurrence From 1960 to 197912 cases of aplastic crisis were seen in 11 children at the rate of $0-2$ per year, the mean frequency for the 20 years being $1 \cdot 2 / 100$ patients/yr. In 1980 the frequency rose to 9.0/100 patients/yr as seven aplastic crises were seen. Those seven cases, together with two occurring in 1979 , have been studied in detail.

Clinical and haematological features Serum specimens were available for virus studies from the nine cases presenting in 1979-1980 and some of the clinical and haematological features of these are shown in Table 1. Eight patients had had symptoms for 1-7 days before attending hospital. The exception was a patient already in hospital recovering from an episode of lung consolidation. Fever $\left(37 \cdot 2-40 \cdot 5^{\circ} \mathrm{C}\right)$ was present in eight cases and in seven the axillary temperature exceeded $37.7^{\circ} \mathrm{C}$, the upper limit attributable to anaemia. Pain was present in eight but it was not the main reason for coming to hospital.

On presentation eight patients had a haemoglobin of 2.8 to $6.3 \mathrm{~g} / \mathrm{dl}$ which represented a fall from their steady state values. The ninth patient had not previously been seen at the hospital but on presentation the haemoglobin was $3.7 \mathrm{~g} / \mathrm{dl}$, which is uncharacteristically low for SCA in the steady state. Peripheral blood reticulocytes were less than $1 \%$ in eight cases. In the ninth the reticulocytes were $5.1 \%$ but since there was no evidence of acute haemorrhage or excessive haemolysis and he was not seen until seven days after the onset of symptoms, it is believed that he was in the recovery phase of an aplastic crisis and the marked erythropoiesis in his bone marrow supported this. Single bone-marrow aspirates from seven cases taken 2-8 days after the onset of the clinical symptoms were examined. These samples showed the features previously described $^{910}$ which depend on the stage of the illness. Initially there was a virtual absence of red cell precursors, only a few pronormoblasts and an occasional early pronormoblast being found. Subsequently there was proliferation of the pronormoblasts and appearance of large forms as previously described. " Still later there was massive proliferation of the early, intermediate and late normoblasts.

Table 1 Clinical and haematological features of children in aplastic crisis

\begin{tabular}{|c|c|c|c|c|c|}
\hline \multirow[t]{2}{*}{ Case (date) } & \multirow[t]{2}{*}{ Age (yr) } & \multirow[t]{2}{*}{ Symptoms } & \multirow[t]{2}{*}{ Temperature $\left({ }^{\circ} \mathrm{C}\right)$} & \multicolumn{2}{|c|}{$\begin{array}{l}\text { Peripheral blood findings on presentation } \\
\text { (last steady state result) }\end{array}$} \\
\hline & & & & $H b(g / d l)$ & Reticulocytes (\%) \\
\hline $\begin{array}{l}1 \\
(18.4 .79) \\
2 \\
(11.11 .79) \\
3 \\
(4.4 .80) \\
4 \\
(10.7 .80) \\
5 \\
(14.7 .80) \\
6^{*} \\
(6.11 .80) \\
7^{*} \\
(11.11 .80) \\
8^{*} \\
(15.12 .80) \\
9^{*} \\
(21.12 .80)\end{array}$ & $\begin{array}{r}6 \\
9 \\
2 \\
9 \\
10 \\
7 \\
11 \\
4 \\
7\end{array}$ & $\begin{array}{l}\text { Headache, pain in back and abdomen. } \\
\text { Vomiting for } 7 \text { days. } \\
\text { Headache, sore throat and } \\
\text { lymphadenopathy for } 3 \text { days. } \\
\text { Abdominal pain and distension for } 2 \text { days. } \\
\text { Headache and fever for } 3 \text { days. } \\
\text { Recovery from lung consolidation. } \\
\text { Felt unwell for } 1 \text { day. } \\
\text { Pain in abdomen and chest for } 6 \text { days. } \\
\text { Dizziness and pallor for } 1 \text { day. } \\
\text { Dyspnoea, retrosternal pain, dizziness, } \\
\text { headache and fever for } 2 \text { days. } \\
\text { Pain left foot and pallor for } 4 \text { days, } \\
\text { dizziness. } \\
\text { Headache and anorexia for } 2 \text { days. }\end{array}$ & $\begin{array}{l}37 \cdot 2 \\
39 \cdot 0 \\
37 \cdot 9 \\
38 \cdot 2 \\
40 \cdot 5 \\
39 \cdot 5 \\
38 \cdot 0 \\
36 \cdot 8 \\
38 \cdot 5\end{array}$ & $\begin{array}{l}3.4(7.0) \\
6.3(8.4) \\
3.7(-) \dagger \\
5.8(7.3) \\
5.7(9.2) \\
3.3(8.3) \\
5.1(8.0) \\
2.8(7.5) \\
5.3(7.0)\end{array}$ & $\begin{array}{c}5.1(6.0) \\
0.2(11.0) \\
0.9(-) \dagger \\
0.6(4.6) \\
<0.2(8.0) \\
<0.2(13.6) \\
<0.2(12.0) \\
<0.2(11.8) \\
0.4(12.7)\end{array}$ \\
\hline
\end{tabular}

*Cases 6 and 7 were siblings, as were 8 and 9. †Patient not previously seen at King's College Hospital. 
There were no apparent changes in the granulocyte precursors or megakaryocytes. However, the peripheral blood platelets showed a tendency to fall. Our own findings for platelet levels in children of this age with SCA in the steady state showed a range of $202-475 \times 10^{9} / 1$. By this criterion six showed a thrombocytopenia at some stage, the lowest level for these patients being in the range $60-150 \times 10^{9} / 1$. The remainder showed a fall from their steady state platelet counts but not an absolute thrombocytopenia.

At the time of presentation only one of the nine cases had a leucopenia and this was due to a low neutrophil count of $1.5 \times 10^{9} / 1$. None had a lymphopenia. After the initial blood count interpretation of peripheral blood measurements was complicated by the transfusions given as part of the treatment of the aplastic crises. However, one further patient developed a neutropenia but three exhibited a neutrophilia in the week after presentation.

None of the nine patients was transfused in the month prior to their aplastic crisis. Eight of the nine had not been transfused in the previous six months but the ninth had received four units of packed cells three months before presenting in aplastic crisis.

Virus studies The results of tests for viral antigen and antibody are summarised in Table 2. Viral antigen was detected by CIE in the acute-phase specimen of five of the cases of aplastic crisis (cases 2, 4, 5,7 and 9, Table 1). The acute-phase serum of six of the nine patients was taken within 1-3 days of the onset of symptoms and the five virus positive specimens were in this group. The acute-phase specimen of three patients (cases 1, 6 and 8) was taken 4-7 days after the onset of symptoms and viral antigen could not be detected in any of these specimens. Virus particles could be seen in all five sera which were CIE antigen positive. This could be achieved by direct electron microscopy in some specimens but the clarity of the preparations and ease of finding virus were much improved by IEM. The particles appear as small round particles with a mean diameter of $21 \mathrm{~nm}$ (Figure). Particles penetrated by stain are frequently seen and these tend to reveal a hex-

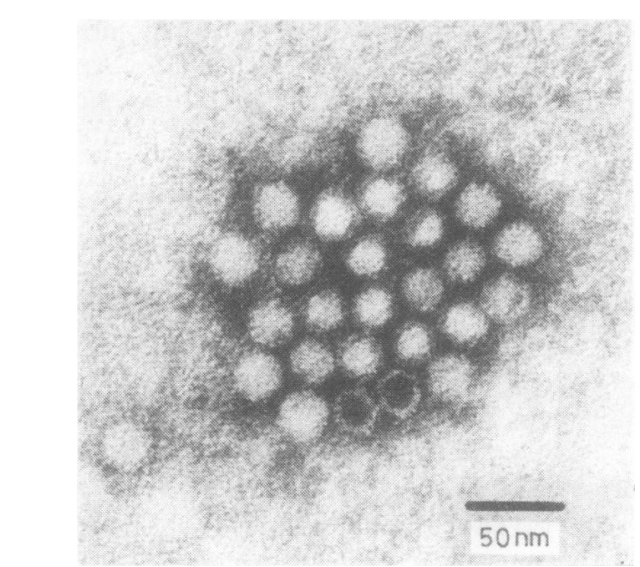

Clump of virus particles from one of the cases of aplastic crisis seen by IEM. Magnification $\times 200000$. Bar $=50 \mathrm{~nm}$.

agonal outline. Four of the five virus positive specimens were tested by immunodiffusion and all four gave lines of identity with each other and with parvovirus B19.

Convalescent sera from all nine cases were virus antibody positive by CIE. This test also demonstrated seroconversion in the five viral antigen positive cases. In one case the acute-phase specimen was both antigen and antibody positive but a serum taken 11 days prior to presentation in aplastic crisis was negative for both. Three were antibody negative in the acute phase specimen but sera taken 9 ( 2 cases) and 11 days after presentation in aplastic crisis were positive. In the fifth case the acute-phase specimen was-antigen positive/antibody negative but the second serum which was antigen negative/ antibody positive was not taken until six months after the aplastic crisis. Late follow-up specimens were available from seven of the nine cases and in all these seven cases CIE antibody persisted for at least nine months.

Specific antibody of the IgM class to the parvovirus-like agent was detected in 4 of the 5 antigen-positive cases, the exception being the case in which there was a six months interval between

Table 2 Occurrence of the parvovirus-like agent and its antibody in children with sickle-cell anaemia and controls

\begin{tabular}{|c|c|c|c|c|}
\hline & \multicolumn{3}{|c|}{ Sickle-cell anaemia } & \multirow[t]{2}{*}{ Controls } \\
\hline & Aplastic crisis & Others & Total & \\
\hline $\begin{array}{l}\text { Number } \\
\text { Viral antigen detected } \\
\text { Antibody positive by CIE (\%) } \\
\text { Seroconversion by CIE } \\
\text { Specific IgM antibody present }\end{array}$ & $\begin{array}{l}9 \\
5 \\
9 \\
5 \\
8\end{array}$ & $\begin{array}{r}59 \\
0 \\
18 \\
7 \\
5\end{array}$ & $\begin{array}{l}68 \\
5 \\
27(39 \cdot 4) \\
12 \\
13\end{array}$ & $\begin{array}{l}115 \\
0 \\
24(21) \\
\text { Not applicable } \\
0^{*}\end{array}$ \\
\hline
\end{tabular}


sera. Specific IgM was detected in only one of the five antigen positive acute-phase sera but was detected in all sera from these four cases taken between 3 and 14 days after presentation. In one case IgM antibody persisted for three months.

In the four cases in whom viral antigen was not detected antibody was detected by CIE in the first serum samples which were taken $2,4,6$ and 7 days after the onset of symptoms. All these specimens and a further specimen from each patient taken $1-4$ weeks later were positive for specific IgM to the parvovirus-like agent.

\section{OTHER CHILDREN WITH SICKLE CELL DISEASE} Clinical fundings One hundred and forty-two serum specimens from 59 other children with sickle cell anaemia were available for investigation. In 31 of these patients paired or serial specimens were sent as part of the routine management of their hospital admissions. In the two years of the study many of these children had more than one admission and the episodes investigated were as follows: 17 upper respiratory tract infections in 11 patients, 4 lower respiratory tract infections in 4 patients, 16 painful crises in 8 patients, 3 sequestration crises in one patient and a miscellaneous group consisting of two cases of pyrexia of unknown origin and one each of abdominal pain, epileptic fit, fatal pneumococcal septicaemia, erythematous rash, chicken pox and urinary tract infection. One hundred and fourteen sera were sent from these 31 patients. A serum specimen was taken from the other 28 children when they attended outpatients for a routine visit.

Virus studies Viral antigen was not found in any of the 142 sera from the 59 patients (Table 2). However, 18 members of the group were viral antibody positive at some stage during the study. From eight of these only one specimen was tested. From three others specimens taken in 1979, 1980 and 1981 were tested and all specimens were antibody positive. None of the specimens from these 11 patients contained specific IgM to the parvovirus-like agent. Of the 11 patients one had had an aplastic crisis in 1978 and another had had two, one in 1970 in association with pneumococcal meningitis and septicaemia and another in 1975. Three of the children who were antibody negative in 1980 had a history of aplastic crises 4,6 and 12 years previously.

The seven other antibody-positive patients seroconverted during the period studied. The timing of the serial specimens in six of these patients allowed the seroconversion to be placed within a 2-6 week period. The first antibody-positive specimens were taken from these patients during or shortly after admissions for the following reasons: upper respiratory tract infection, plus retrosternal and hip pain; back pain; upper respiratory tract infection ( 2 cases) and possible chest infection (2 cases). During the admission prior to seroconversion the haemoglobin concentration and reticulocyte counts were not significantly different from the steady state values for the six patients. In five of these six patients the first antibody-positive specimen contained specific IgM to the parvovirus-like agent but in the case of the sixth patient it did not. Each of these five patients with specific IgM had been transfused (1-3 units of packed cells) during the month prior to their first antibody-positive specimen but the IgM negative individual had not been.

The seventh patient who seroconverted did so between 29 October 1980 and 6 May 1981. A specimen taken on the latter date did not contain specific IgM to the parvovirus-like agent. The patient had cholecystitis and had his gall bladder and appendix removed in June 1981 but was not transfused prior to the first antibody-positive sample.

\section{Controls}

A serum specimen, taken in 1980 from each of 115 children (aged 1-15 yr) who did not have SCA, and received in the routine diagnostic laboratory, was tested. None contained viral antigen but $24(21 \%)$ were viral antibody positive by CIE. This contrasts with $30 \%$ in the children with SCA who did not have an aplastic crisis and $39.4 \%$ in the SCA group as a whole (Table 2).

\section{Persistence of parvovirus antibody by CIE}

In one of the children with SCA who was antibody positive in all specimens tested, three pairs of specimens were taken in September/October 1979, May/June 1980 and February/March 1981. When all six sera were tested in the same CIE plate a gradual diminution in the amount of antibody present was noted. The precipitin lines became fainter in successive sera and the position of the lines moved closer to the well containing the patient's serum. The precipitin line in the last serum is only just detectable. A similar phenomenon was observed in one of the patients who had an aplastic crisis and from whom nine specimens were taken during the nine months after the episode of aplasia.

\section{HbF studies}

The HbF levels in children presenting with aplastic crisis were compared with those of the children with asymptomatic primary infection. Age and sex matched children with sickle cell anaemia who did not have an infection with the parvovirus-like agent during the study period were used as controls. In 
order to avoid the effects of blood transfusion on the $\mathrm{HbF}$ levels values obtained in the steady state 3-9 months prior to aplastic crisis or seroconversion were used for comparison. The mean $\mathrm{HbF}$ value of the nine children presenting in aplastic crisis was $7 \cdot 5 \%$ with a range of $2 \cdot 4-13 \cdot 4$. For the five asymptomatic seroconversions the mean was 6.4 and the range $2 \cdot 5-17 \cdot 3$. The corresponding figures for 14 controls were $7 \cdot 8$ and $2 \cdot 0-23 \cdot 0$.

\section{Discussion}

Nine cases of aplastic crisis were seen during the course of the study. The vague virus-like antecedent symptoms, the peripheral blood haemoglobin and reticulocyte findings and the appearances of the bone marrow are consistent with previous descriptions of the condition. No consistent changes in peripheral blood leucocytes was found but there was a suggestion of a diminution of platelet numbers which has not previously been described.

Infection with the parvovirus-like agent at the time of the aplastic crisis was proved by detection of viraemia and/or the presence of specific IgM in all nine cases. These results are in accord with the findings from Jamaica ${ }^{5}$ in which many cases occurring in 1979-80 were associated with infection with the same parvovirus-like agent. The period 1979-81 was one of high incidence of aplastic crises both in the UK and Jamaica, the rate of occurrence being $9 / 100$ cases of SCA at King's College Hospital and $10 / 100$ cases in the cohort clinic in Jamaica. ${ }^{5}$ Undoubtedly aplastic crises can occur in association with other infections such as salmonella, ${ }^{112}$ virus pneumonia, ${ }^{13}$ pneumococcal infection ${ }^{5}$ and possibly Mycoplasma pneumoniae. ${ }^{14}$ Nevertheless most cases of aplastic crises investigated in the past have not been associated with a specific infection and we conclude from this study and the work of others ${ }^{5}$ that the parvovirus-like agent is a common cause of aplastic crises in children with SCA. Clearly in certain high incidence years such as 1979-80 it is responsible for the majority of cases. Retrospective study of cases which occurred in earlier years is not possible since the results presented here indicate that, in some individuals, antibody becomes undetectable by CIE 12-24 months after infection.

An aplastic crisis is not an inevitable consequence of infection with the parvovirus-like agent in children with SCA. Serjeant $e a^{5}{ }^{5}$ observed that not all children with SCA who were antibody positive had a history of an aplastic crisis. In this study nine of 11 children with SCA who were antibody positive on first testing had no such history. Moreover during the two years of the study we identified seven seroconversions in the absence of an aplastic crisis.
In one of these no specific IgM was detected in an early convalescent serum, suggesting a reinfection. In another the period between the two sera was seven months and no conclusions could be drawn concerning primary infection or reinfection. However, in five instances the presence of specific IgM indicated primary infection. A possible explanation would be that these five patients had higher $\mathrm{HbF}$ concentrations than the patients with aplastic crises. $\mathrm{High} \mathrm{HbF}$ is associated with longer red cell life span and this would compensate better for a temporary failure of red cell production. No such difference in $\mathrm{HbF}$ concentration was found. However it was noted that all five patients who had a primary asymptomatic infection were transfused with packed cells in the month prior to seroconversion. By contrast none of the cases presenting with aplastic crisis had been transfused in the previous month and only one of them had been transfused in the previous six months. Transfused red cells from normal donors will tend to mask an aplastic crisis. Moreover small amounts of antibody may be passively transferred during transfusion (we find about $30 \%$ of blood donors have antibody detectable by CIE). Such antibody cannot account for the seroconversion and the IgM studies indicate that recent active infection had occurred. However, passive immunisation by small amounts of antibody during transfusion could modify a subsequent infection with the parvoviruslike agent from one which produced an aplastic crisis to one which produced an asymptomatic seroconversion.

SE Jones is supported by a grant from the National Fund for Research into Crippling Diseases and $L$ Murtaza by a grant from the Leverhulme Trust. The Rayne Management Committee provided research facilities.

\section{References}

' Cossart YE, Field AM, Cant B, Widdows D. Parvovirus-like particles in human sera. Lancet 1975;i:72-3.

${ }^{2}$ Paver WK, Clarke SKR. Comparison of human fecal and serum parvo-like viruses. J Clin Microbiol 1976;4:67-70.

${ }^{3}$ Schneerson JM, Mortimer PP, Vandervelde EM. Febrile illness due to a parvovirus. $\mathrm{Br}$ Med $J$ 1980;ii: 1580 .

4 Pattison JR, Jones SE, Hodgson J, et al. Parvovirus infections and hypoplastic crisis in sickle-cell anaemia. Lancet $1981 ; \mathrm{i}: 664-5$.

${ }^{s}$ Serjeant GR, Topley JM, Mason K, et al. Outbreak of aplastic crises in sickle-cell anaemia associated with parvovirus-like agent. Lancet 1981 ;ii:595-7.

- Anderson Nan, Doane FW. Specific identification of enteroviruses by immuno-electron microscopy using a serum-in-agar diffusion method. Can J Microbiol 1973;19:586-9.

' Anderson MJ, Davis LR, Jones SE, Pattison JR, Serjeant GR. The development and use of an antibody capture radioimmunoassay for specific IgM to a human parvovirus-like agent. J Hyg 1982;88:309-24. 
Stamm WP, Phillips EA. A cellulose acetate membrane precipitation (CAP) for amoebiasis. Trans $R$ Soc Trop Med Hyg 1977;71:490-2.

${ }^{9}$ Leiken SL. The aplastic crisis of sickle-cell disease. Am J Dis Child 1957;93:1289.

${ }^{10}$ MacIver JE, Parker-Williams EJ. The aplastic crisis in sickle-cell anaemia. Lancet $1961 ; \mathrm{i}: 1068-89$.

"Chernoff AI, Josephson AM. Acute erythroblastopaenia in sickle-cell anaemia and infectious mononucleosis. Am J Dis Child 1951;82:310-22.

${ }^{12}$ Megas H, Papadaki E, Constantinides B. Salmonella septicaemia and aplastic crisis in a patient with sickle-cell anaemia. Acta Pediatr 1961;50:517-21.
${ }^{13}$ Singer K, Motulsky AG, Wile SA. Aplastic crisis in sickle-cell anaemia. J Lab Clin Med 1950;35:721-36.

14 Mann JR, Cotter KP, Walker RA, Bird GWG, Stuart J. Anaemic crisis in sickle-cell disease. J Clin Pathol 1975;28:341-4.

Requests for reprints to: Professor JR Pattison, Department of Medical Microbiology, King's College Hospital Medical School, Denmark Hill, London SE5 8RX, England. 